\title{
Myocardial Protection of Contractile Function After Global Ischemia by Compound $K$ in the Isolated Heart
}

\author{
Jong-Hoon Kim* \\ Department of Veterinary Physiology, College of Veterinary Medicine, Chonbuk National University, \\ Biosafety Research Institute, 664-14, 1GA, Duckjin-Dong, Duckjin-Gu, Jeonju City, Jeollabuk-Do 561-756, Korea \\ (Received November 18, 2009; Revised December 11, 2009; Accepted December 12, 2009)
}

\begin{abstract}
Ginsenosides are among the most well-known traditional herbal medicines frequently used for the treatment of cardiovascular symptoms in South Korea. The anti-ischemic effects of compound K (CK), a metabolite of ginsenoside $\mathrm{Rb} 1$, on ischemia-induced isolated rat hearts were investigated through the analyses of the changes in the hemodynamics (blood pressure, aortic flow, coronary flow, and cardiac output) and the measurement of the infarct region. The subjects in this study were divided into four groups: the normal control, the CK-alone group, the ischemia-induced group without any treatment, and the ischemia-induced group treated with CK. No significant differences in perfusion pressure, aortic flow, coronary flow, and cardiac output were found between the groups before ischemia was induced. The oxygen and buffer supply was stopped for $30 \mathrm{~min}$ to induce ischemia $60 \mathrm{~min}$ after reperfusion in the isolated rat hearts, and the CK was administered $5 \mathrm{~min}$ before ischemia induction. The CK treatment significantly prevented decreases in perfusion pressure, aortic flow, coronary flow, and cardiac output under ischemic conditions. In addition, the hemodynamics (except for the heart rate) of the group treated with CK significantly recovered $60 \mathrm{~min}$ after reperfusion, unlike in the control group. CK significantly limited the infarct. These results suggest that CK treatment has distinct anti-ischemic effects in an $e x$ vivo model of an ischemia-reperfusion-induced rat heart.
\end{abstract}

Key words : compound $\mathrm{K}$, isolated heart, ischemia-reperfusion injury, hemodynamics, cardioprotective effect

\section{INTRODUCTION}

Panax ginseng has been popularly used as a herbal medicine in Asia for more than 2000 years and currently occupies an important place among the tonic remedies of oriental medicine. Ginseng's genus name Panax is derived from the Greek words pan (all) and akos (cure), meaning cure-all. Ginseng root has been used extensively in Korean and Chinese medicine and has become increasingly popular in the western world for its alleged tonic effect and possible curative and restorative properties. There are increased clinical evidences concerning the potential benefits of ginseng roots in cardiovascular diseases. Administration of ginsenosides, a mixture of saponins extracted from Panax ginseng, decreases blood pressure in both hypertensive patients and experimental animals. ${ }^{1,2)}$ Ginsenosides, which is considered to be a biologically active fraction of $P$. ginseng, is a mixture of triterpene glycosides. The major components of ginsenosides

\footnotetext{
* Corresponding author. E-mail: jhkim1@ @chonbuk.ac.kr
} Phone: +82-63-270-2563, Fax: +82-63-270-3780 belong either to the protopanaxadiol or protopanaxatriol groups. ${ }^{3)}$ It has also been shown that ginsenosides enhance vasodilatory response to perivascular nerve stimulation in monkey cerebral arteries. ${ }^{4)}$ The antihypertensive effects of ginsenosides may result from their ability to inhibit vascular tone. In previous study, it was showed that ginsenoside $\mathrm{Rg}_{3}$ inhibited $\mathrm{Ca}^{2+}$-induced vascular contraction, ${ }^{5,6)}$ and that the intracellular accumulation of $\mathrm{Ca}^{2+}$ is a crucial factor for the irreversible myocardial injury that occurs after reperfusion following a prolonged period of ischemia. ${ }^{78)}$ According to Bourdillon and Poole-Wilson, ${ }^{9)}$ the accumulation of $\mathrm{Ca}^{2+}$ was not due to a decrease in efflux, but due to an increase in influx. The mechanisms of ischemia/reperfusion (I/R) injury include the production of reactive oxygen species (ROS), abnormal lipid metabolism, and calcium overload. ${ }^{10)}$ It has been well known that $\mathrm{Ca}^{2+}$ overload due to $\mathrm{Na}^{+}-\mathrm{Ca}^{2+}$ exchange and L-type calcium channel opening leads to increase $\left[\mathrm{Ca}^{2+}\right] \mathrm{i} .{ }^{11)}$ And, it was reported that excessive accumulation of cytosolic $\mathrm{Ca}^{2+}$ is taken up by mitochondria during $\mathrm{I} / \mathrm{R}$, resulting in an increase in mitochondrial $\mathrm{Ca}^{2+}$ level, 
which may stimulate the opening of the mitochondrial permeability transition and the release of proapoptotic factors. ${ }^{12,13)}$ However, it is not reported for any antiischemic effect of compound $\mathrm{K}(\mathrm{CK})$, a metabolite of ginsenoside Rb1, ex vivo. In addition, because of the adverse effects associated with anti-ischemia drugs, many trials have been recently performed to find and develop new anti-ischemic drugs through herbal medicines that would minimize side effects. Numerous studies of various herbal medicines have been performed, and some have reported significant improvements in controlling ischemic symptoms without any noticeable adverse effects. ${ }^{14)}$ Given those backgrounds, we previously showed that ginsenoside metabolite $\mathrm{CK}$ inhibited $\mathrm{Ca}^{2+}$ channel subtype, ${ }^{15)}$ providing new insights into one possible mechanism underlying the beneficial effects of ginsenosides in the cardiovascular and nervous systems. However, since activity in vitro does not necessarily reflect in organ level activity, the current study was conducted to determine whether the apparent activity of CK on cardioprotection was reflected ex vivo using perfused heart model. After all, after we determined the maximum effective dose of CK during I/R injury, we intensively examined the cardioprotective effects of the CK using an ex vivo Langendorff system.

\section{METERIAL AND METHODS}

\section{Drugs}

As shown in Fig. 2, CK was kindly obtained from Korea Ginseng Corporation (Daejon, Korea). Compound $\mathrm{K}$ was dissolved in DMSO as a concentrated stock and further diluted to its final concentration in saline. When ischemia was started, the stock solutions of $\mathrm{CK}$ was diluted with perfusate before use. We found the final concentration of DMSO $(<0.01 \%)$ had no effect on the neuronal cell (data not shown). All other chemical agents were purchased from Sigma (St. Louis, MO, USA) unless otherwise specified.

\section{Animals}

Male Sprague-Dawley rats weighing 250 to $300 \mathrm{~g}$ were supplied by Charles River (KFT). The rats were fed a standard rodent pellet chow and housed with free access to commercial food pellets (LSM, Bacutil, Poland), as well as tap water ad libitum under strictly controlled pathogen-free conditions (room temperature: $23 \pm 1^{\circ} \mathrm{C}$,

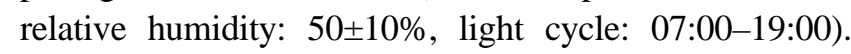
And, the rats were acclimatized to their environment for 2 weeks before commencement of the experiments. All the animals was kept in light (L)-dark (D) conditions L:D = 12:12. The investigation conformed to the Guide for the Care and Use of Laboratory Animals published by the US National Institutes of Health (NIH Publication No. 85-23, revised 1996) and was approved by the the "Guideline for Institutional Animal Care and Use Committees (IACUC)" of Chonbuk National University (Jeonju, Korea).

\section{Experimental protocol}

The subjects in this study were divided into four groups $(\mathrm{n}=12$, each group): normal control group, $100 \mu \mathrm{M} \mathrm{CK}$ control group, an ischemia control group, and $100 \mu \mathrm{M}$ CK administrated group before ischemia. Forty eight animals were randomly divided into four groups, A1: normal control group with modified modified KrebsHenseleit (KH) solution, A2: $100 \mu \mathrm{M}$ CK control group with no ischemia, A3: ischemia control group with no administration of CK and A4: $100 \mu \mathrm{M} \mathrm{CK}$ administrated group with I/R induction (administration of $100 \mu \mathrm{M} \mathrm{CK}$ before ischemia followed by reperfusion with modified KH buffer for $60 \mathrm{~min}$ ). Namely, $100 \mu \mathrm{M}$ CK was added 5 min before ischemia were induced in isolated hearts. All hearts were perfused for $20 \mathrm{~min}$ before the following perfusion protocol for equilibration (Fig. 1).

\section{Heart preparation and perfusion apparatus}

Sprague Dawley rats were anesthetized with intraperitoneal pentobarbital sodium $(50 \mathrm{mg} / \mathrm{kg})$. Heparin $(1000 \mathrm{U} /$ $\mathrm{kg}$ ) was injected through a femoral vein to prevent blood coagulation. The hearts were rapidly excised and placed in ice-cold $\left(4^{\circ} \mathrm{C}\right)$ Krebs-Henseleit $(\mathrm{KH})$ bicarbonate buffer $\left(\mathrm{NaCl} 120.0 \mathrm{mM}, \mathrm{NaHCO}_{3} 25 \mathrm{mM}, \mathrm{KCl} 4.8 \mathrm{mM}\right.$, $\mathrm{KH}_{2} \mathrm{PO}_{4} 1.2 \mathrm{mM}, \mathrm{CaCl}_{2} 1.25 \mathrm{mM}, \mathrm{MgSO}_{4} 1.2 \mathrm{mM}$, and glucose $11.0 \mathrm{mM}$ ). Aorta and left atrium cannulation was performed rapidly, and the hearts were perfused in Langendorff mode at a pressure of $100 \mathrm{~cm} \mathrm{H}_{2} \mathrm{O}$ with $\mathrm{KH}$ buffer. The buffer was saturated with $95 \% \mathrm{O}_{2} / 5 \% \mathrm{CO}_{2}$ at $\mathrm{pH} 7.4$ and thermostatically kept at a constant temperature of $37^{\circ} \mathrm{C}$. Global ischemia was achieved by clamping both the aortic and atrial lines for $10 \mathrm{~min}$. In Langendorff perfusion (non-working heart model), perfusion fluid entered the heart via the aorta retrograde from the aortic reservoir located $100 \mathrm{~cm}$ above the heart. The aortic reservoir, which was the thermostatically maintained oxygenator, carried out a perfusate to the aorta at a $100 \mathrm{~cm} \mathrm{H}_{2} \mathrm{O}$ hydrostatic pressure maintained with the use of a constant head device (CHD). This system maintains the function of the heart, but does not maintain circulation of perfusate to 

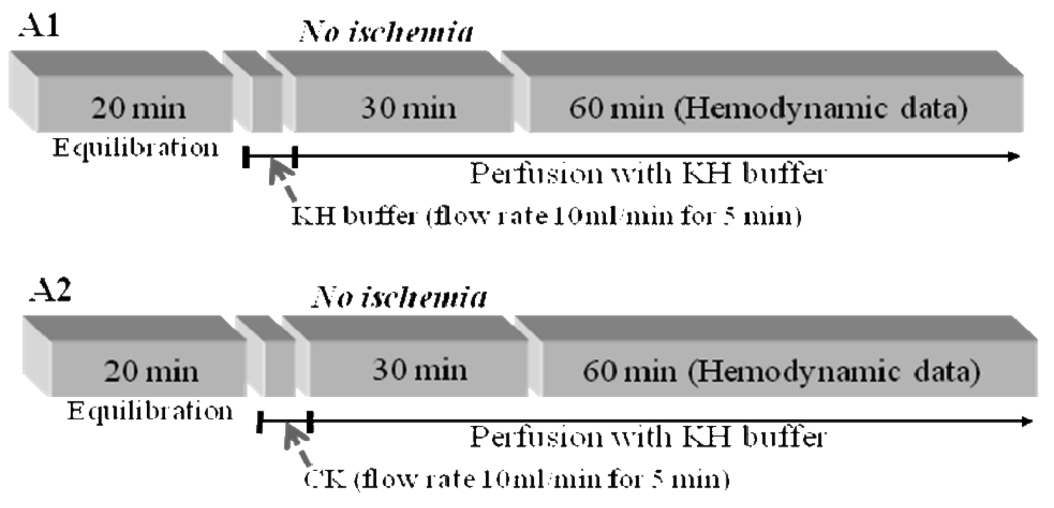

13

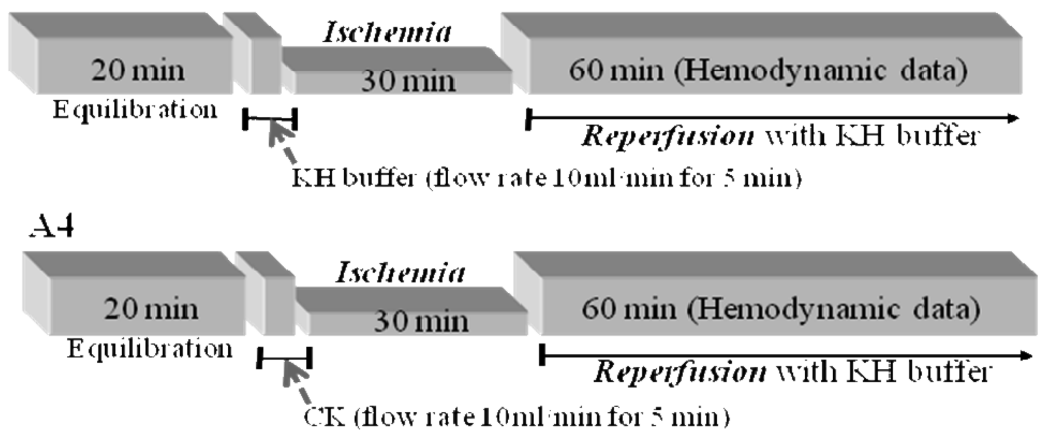

Fig. 1. Experimental protocol. All experimental groups began with a 20 min perfusion period to allow for stabilization of the isolated hearts. Then, the hearts were divided into the normal control group (A1), the CK control group (A2), the ischemia control group (A3) and the CK administrated group (A4), which received administration of CK before ischemia induction.

the ventricle. Such a system is used to recover and maintain heart function for $15 \mathrm{~min}$ after isolation and ischemia induction. In the working heart model, the left atrium cannula and aortic cannula were open and perfusion fluid entered the heart via the left atrium from an atrial bubble trap located $20 \mathrm{~cm}$ above the heart. The left ventricle ejected perfusate via the aorta and elasticity chamber (aortic pressure chamber) against a $20 \mathrm{~cm} \mathrm{H}_{2} \mathrm{O}$ hydrostatic pressure to the aortic bubble trap. The same system is used to maintain heart function 20 min before induction of heart ischemia, and to recover heart function for 60 min after ischemia using the Langendorff system. The system makes it possible to compare the recovery of heart function before and after induction of heart ischemia. Aortic and coronary perfusates were not recirculated in the present study. The entire apparatus was thermostatically maintained by a water jacket and coil heat chamber. Aortic flow and coronary flow were measured by timed collection of perfusate from the aortic and pulmonary trunk cannula, respectively. Cardiac output was calculated by summing the aortic and coronary flows. Heart rate was obtained by an ECG monitoring system (S \& W Medico Teknik A/S, Denmark) with three electrodes attached to the epicardium. Systolic and diastolic aortic pressures were measured throughout the working heart model perfusion periods in the aortic outflow line with a hemodynamics monitoring system ( $\mathrm{S} \& \mathrm{~W}$ Medico Teknik A/S, Denmark).

\section{Ischemia induction of isolated-perfused rat heart}

Male Sprague-Dawley rats were anesthetized with intraperitoneal pentobarbital sodium $(50 \mathrm{mg} / \mathrm{kg})$. The hearts were rapidly excised and mounted on a Langendorff apparatus (IPH-W, Labo Support, Osaka, Japan) via the aorta, and then perfused at a constant pressure of $65 \mathrm{mmHg}$ with $\mathrm{KH}$ buffer. The heart was constantly warmed by a circulating water jacket at $37^{\circ} \mathrm{C}$. The buffer was gassed with $95 \% \mathrm{O}_{2} / 5 \% \mathrm{CO}_{2}$ at $\mathrm{pH}$ 7.4. To measure left ventricular pressure, a pressure transducer was connected to the aortic cannula. Heart rate was monitored from left ventricular pressure. Coronary flow was measured by coronary flow volume $(\mathrm{ml} / \mathrm{min})$. After stabilization (non-working system) to $100 \mathrm{~cm} \mathrm{H}_{2} \mathrm{O}$ for $15 \mathrm{~min}$ via the aortic cannula, the perfusion pressure was reduced to $20 \mathrm{~cm} \mathrm{H}_{2} \mathrm{O}$ for $20 \mathrm{~min}$ at the LA cannula (working system), and then ischemia was induced for $5 \mathrm{~min}$ accompanied by the injection of 
CK for $2 \mathrm{~min}$ (flow rate $10 \mathrm{ml} / \mathrm{min}$ ). Then, the perfusate was injected into the aortic line for 2 min to observe the effects of $\mathrm{CK}$ on an ischemia-induced heart. Ischemic conditions were maintained for 3 additional min. The isolated hearts underwent a total $5 \mathrm{~min}$ period of normothermic $\left(37^{\circ} \mathrm{C}\right)$ no-flow ischemia. In the control group, equal volumes of $\mathrm{KH}$ buffer were injected into the aortic line for $2 \mathrm{~min}$. Those hearts were retrograde perfused for 15 min according to the Langendorff method as described by Li et $a l .{ }^{16)}$ to recover heart function. Then, the heart was perfused again through the working heart system for 60 $\mathrm{min}$ in the period of post-ischemia. The functional recovery rates between the ischemia group and ischemia group with the treatment of the $\mathrm{CK}$ after ischemia induction were compared through changes in perfusion pressure, aortic flow, coronary flow, and cardiac output to observe the anti-ischemia effect of the CK.

\section{Measurement of infarct region}

Measurement was performed according to the method as described previously. ${ }^{17)}$ In brief, to determine the extent of myocardial infarction after $60 \mathrm{~min}$ of reperfusion, the left ventricular slices were incubated at $37^{\circ} \mathrm{C}$ in $1 \%$ triphenyltetrazolium chloride (TTC) phosphate buffered saline for $15 \mathrm{~min}$. The outlines of the slices and TTC negative (infarct area) of white colour area were traced and photographed in colour. The sizes of infarct region were estimated by planimetry with Leica QWin software. Infarct regions were expressed as the percent of total area (100\%).

\section{Statistical analysis}

The results are presented as the mean \pm SEM. Statistical significance was compared between the treatment and control groups by Student's $t$-test. Results with a $p<0.05$ were considered statistically significant.

\section{RESULTS AND DISSCUSSION}

\section{Determination of maximal effective dose of the CK}

The maximum effective amount of $\mathrm{CK}$ on ischemiainduced isolated rat heart was assessed by measuring cardiac output, the direct parameter of heart function, with and without $\mathrm{CK}$ after $\mathrm{I} / \mathrm{R}$ while increasing the doses of CK from 1, 3, 10 and $30 \mu \mathrm{M}$. As shown in Fig. 2, there was no difference between groups without and with 100 $\mu \mathrm{M}$ CK under no ischemic conditions (N/C vs. CK alone $=95.45 \pm 2.5$ vs. 95.8 \pm 3.4 ). This result suggests that $\mathrm{CK}$ itself does not influence cardiac output in normal conditions. In the present studies. the maximum recovery

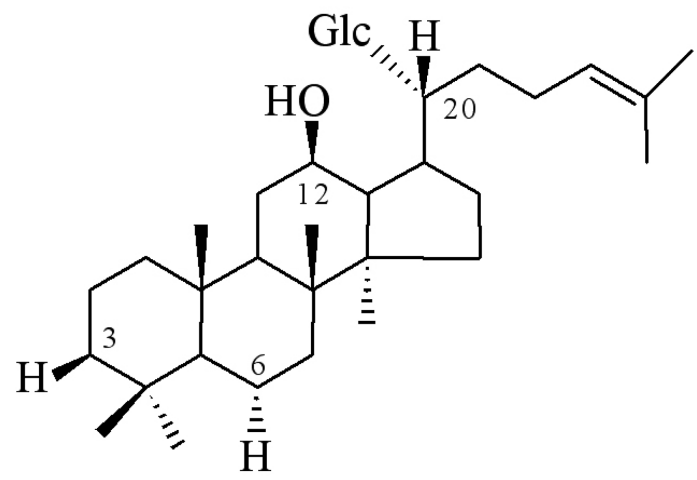

Fig. 2. Chemical structure of compound $\mathrm{K}$, ginsenoside metabolites. Side chains for $\mathrm{CK}$ are $\mathrm{R}_{1}$ and $\mathrm{R}_{2},-\mathrm{H}$ and $\mathrm{R}_{3}$, Glc. Abbreviations for carbohydrates are as follows: Glc. Superscripts indicate the carbon in the glucose ring that links the two carbohydrates.

effect for cardiac output after I/R was obtained with the 100 and $300 \mu \mathrm{M} \mathrm{CK}(58.7 \pm 3.7 v$ s. $60.7 \pm 3.5$, respectively). There was no significantly difference between doses of 100 and $300 \mu \mathrm{M}$ on cardiac output after I/R. However, 100 and $300 \mu \mathrm{M}$ of $\mathrm{CK}$, the concentrations of maximum recovery effect for cardiac output, are very high concentrations for application. Also, the recovery of cardiac output between treatment of $1,3,10$ and $30 \mu \mathrm{M}$ of CK was not significantly different $(42.5 \pm 3.1 \mathrm{ml} / \mathrm{min}$ with 1 $\mu \mathrm{M}, 42.6 \pm 2.9$ with $3 \mu \mathrm{M}, 43.5 \pm 3.8$ with $10 \mu \mathrm{M}$ and $51.5 \pm 3.2 \mathrm{ml} / \mathrm{min}$ with $30 \mu \mathrm{M}$, respectively). Thus, 100 $\mu \mathrm{M}$ was determined to be the appropriate dose of CK, respectively to optimize the anti-ischemic effect on ischemia-induced isolated rat heart (Fig. 3).

\section{Heart rate in I/R-induced isolated rat heart}

Since it is well-known that heart rate does not significantly change under ischemic conditions, ${ }^{18,19)}$ the heart rate of I/R-induced isolated rat heart was assessed. As shown in Table 1, the average heart rate during the preischemic and post-ischemic periods was not significantly different. Also, the heart rate between the control and the CK groups under post-ischemic conditions was not significantly different. These results indicate that heart rate does not change in $\mathrm{I} / \mathrm{R}$-induced isolated rat heart regardless of the treatment of $\mathrm{CK}$.

\section{Recovery effect of the $\mathrm{CK}$ on perfusion pressure}

Perfusion pressure was substantially decreased by $\mathrm{I} / \mathrm{R}$ conditions under post-ischemic periods. However, such decreases were partially recovered by treatments of CK compared with normal control. These anti-ischemic effects 
of $\mathrm{CK}$ on perfusion pressure were continuously observed for 10 to 60 min during the post-ischemic period in each group. Thus, treatment of CK significantly recovered the perfusion pressure reduced by $\mathrm{I} / \mathrm{R}$ for $60 \mathrm{~min}$ post-

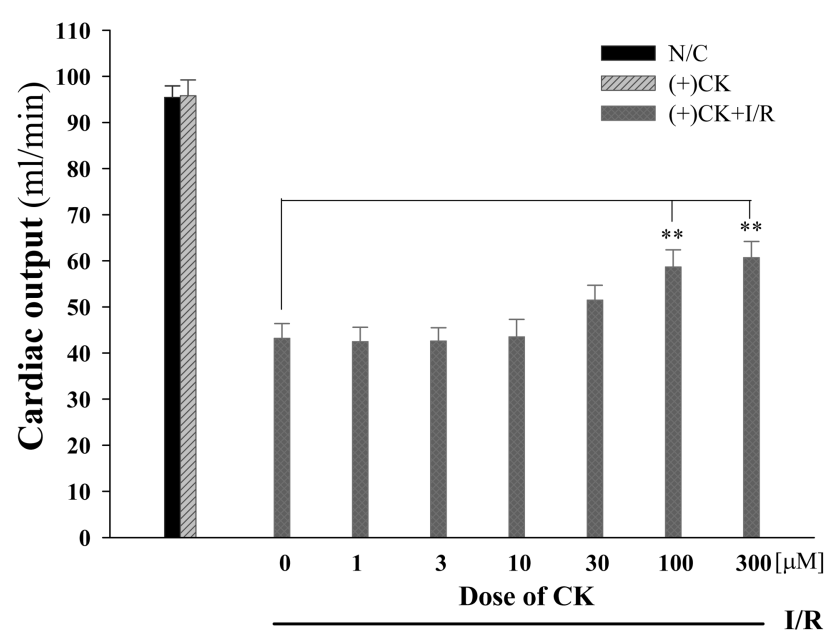

Fig. 3. Determination of maximum dose of that results in maximum anti-ischemic effect. Cardiac output was measured throughout the working heart model perfusion periods in the aortic flow plus coronary flow with a hemodynamic monitoring system in both groups to detect the maximal anti-ischemia effect according to dose of CK (1-300 $\mu \mathrm{M})$. Black histograms represent the mean \pm SEM from twelve rats per control group without any treatment under no ischemia conditions (A1). Striped histograms represent the mean \pm SEM from twelve rats per treatment group of CK under no ischemia conditions (A2). Web histograms represent the mean \pm SEM from twelve rats per treatment group of $\mathrm{CK}$ under post ischemia conditions according to dose of CK (1-300 $\mu \mathrm{M}) .{ }^{*} p<0.01 v s$. control group under ischemic conditions based on Student's $t$-test. ischemia $(* * p<0.01$, Table 2 and Fig. 4). In addition, any effects of CK on perfusion pressure were not significantly observed in corresponding times with ischemia group, namely 5 to 20 min during the pre-ischemic period and 10 to 60 min during the post-ischemic period (normal control

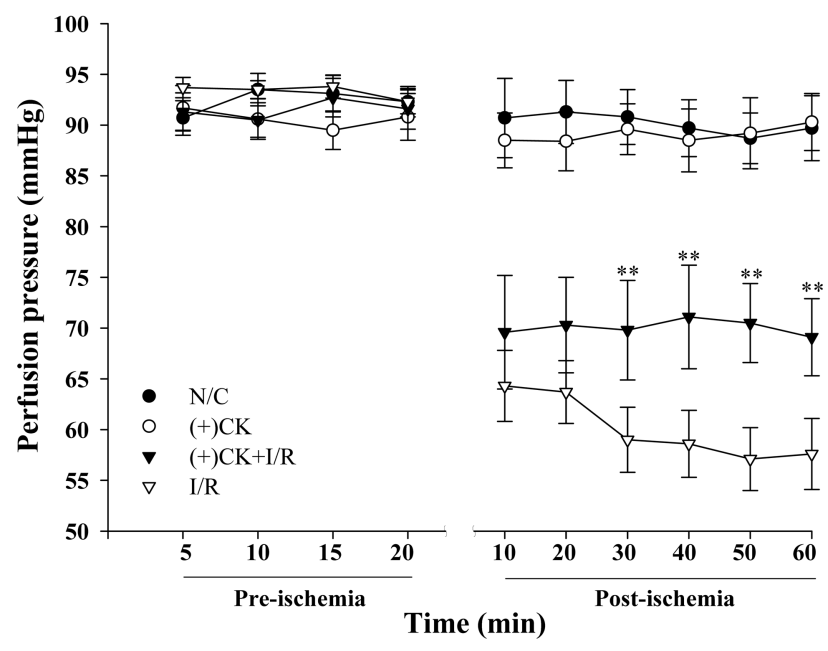

Fig. 4. Recovery effect of the CK on perfusion pressure of ischemia-induced isolated rat heart. Perfusion pressure was measured throughout the working heart model perfusion periods in the aortic outflow line with a hemodynamic monitoring system in the control and treatment groups of $\mathrm{CK}$ to detect an anti-ischemia effect. Each symbol represents the mean \pm SEM from twelve rats per group with (O) denoting the normal control group without any treatment and ischemia (A1), (O) the treatment group of CK under normal conditions without ischemia (A2), ( $\nabla)$ the treatment group of CK under ischemic conditions (A3), and $(\nabla)$ the I/R group without any treatment. $* *<<0.01 v s$. control group under ischemic conditions based on Student's $t$-test.

Table 1. Heart rate in ischemia-induced isolated rat hearts

\begin{tabular}{ccccc}
\hline \hline \multirow{2}{*}{ Groups } & \multirow{2}{*}{ Pre-ischemia (beats/min) } & \multicolumn{3}{c}{ Post-ischemia (beats/min) } \\
\cline { 3 - 5 } & & $10 \mathrm{~min}$ & $30 \mathrm{~min}$ & $60 \mathrm{~min}$ \\
\hline $\mathrm{I} / \mathrm{R}$ & $281.1 \pm 24.6(100.0 \pm 9.2 \%)$ & $279.5 \pm 24.1(99.2 \pm 13.4 \%)$ & $280.3 \pm 25.5(99.6 \pm 12.8 \%)$ & $275.5 \pm 19.7(97.8 \pm 10.4 \%)$ \\
$\mathrm{CK}+\mathrm{I} / \mathrm{R}$ & $270.8 \pm 19.6(100.0 \pm 7.7 \%)$ & $275.7 \pm 22.5(101.7 \pm 8.3 \%)$ & $268.7 \pm 25.3(99.7 \pm 9.5 \%)$ & $265.8 \pm 24.3(98.1 \pm 8.3 \%)$ \\
\hline
\end{tabular}

Table 2. Effects of CK on perfusion pressure

\begin{tabular}{ccccc}
\hline \hline \multirow{2}{*}{ Time $(\min )$} & \multicolumn{4}{c}{ Perfusion pressure for post-ischemia $(\mathrm{mmHg})$} \\
\cline { 2 - 5 } & $\mathrm{N} / \mathrm{C}$ & $\mathrm{CK}$ & $\mathrm{I} / \mathrm{R}$ & $\mathrm{CK}+\mathrm{I} / \mathrm{R}$ \\
\hline 10 & $90.7 \pm 3.9$ & $88.5 \pm 2.7$ & $64.3 \pm 3.5$ & $69.6 \pm 5.6$ \\
20 & $91.3 \pm 3.1$ & $88.4 \pm 2.9$ & $63.7 \pm 3.1$ & $70.3 \pm 4.7$ \\
30 & $90.8 \pm 2.7$ & $89.6 \pm 2.5$ & $59.0 \pm 3.2$ & $69.8 \pm 4.9$ \\
40 & $89.7 \pm 2.8$ & $88.5 \pm 3.1$ & $58.6 \pm 3.3$ & $71.1 \pm 5.1$ \\
50 & $88.7 \pm 2.5$ & $89.2 \pm 3.5$ & $57.1 \pm 3.1$ & $70.5 \pm 3.9$ \\
60 & $89.7 \pm 3.2$ & $90.3 \pm 2.8$ & $57.6 \pm 3.5$ & $69.1 \pm 3.8$ \\
\hline
\end{tabular}


vs. CK, $p>0.05$, Tabel 2, Fig. 4).

\section{Recovery effect of the CK on aortic flow}

Aortic flow was substantially decreased by I/R compared with normal control under post-ischemic conditions. However, such decreases were recovered by treatments of CK. These anti-ischemic effects of CK on aortic flow were continuously observed for 10 to $60 \mathrm{~min}$ during the post-ischemic period in each group. Thus, treatment of CK significantly recovered the aortic flow reduced by ischemia for $60 \mathrm{~min}$ post-ischemia $(* * p<0.01$, Table 3 and Fig. 5). Also, any effects of CK on aortic flow were not significantly observed in corresponding times with ischemia group alike perfusion pressure (normal control vs. CK, $p>0.05$, Tabel 3, Fig. 5).

\section{Recovery effect of the CK on coronary flow}

Induction of ischemia elicits a substantial decrease in coronary flow compared to control. However, treatment of CK dramatically recovered coronary flow under no ischemic conditions. Such recovery continued from 30 to $60 \mathrm{~min}$ in the working heart model after ischemia was induced. As well as aortic flow, any difference between normal control and the $\mathrm{CK}$ alone group on coronary flow were not significantly observed in corresponding times with ischemia group for 5 to 20 min during the pre-ischemic period and 10 to 60 min during the post-ischemic period (normal control $v s$. CK, $p>0.05$, Tabel 4, Fig. 6).

\section{Recovery effect of the CK on cardiac output}

Cardiac output was substantially decreased by induction of ischemia compared with normal control. However, such decreases were significantly recovered by the treatment of CK under no ischemic conditions. Thus, in the working heart model during the post-ischemic period,

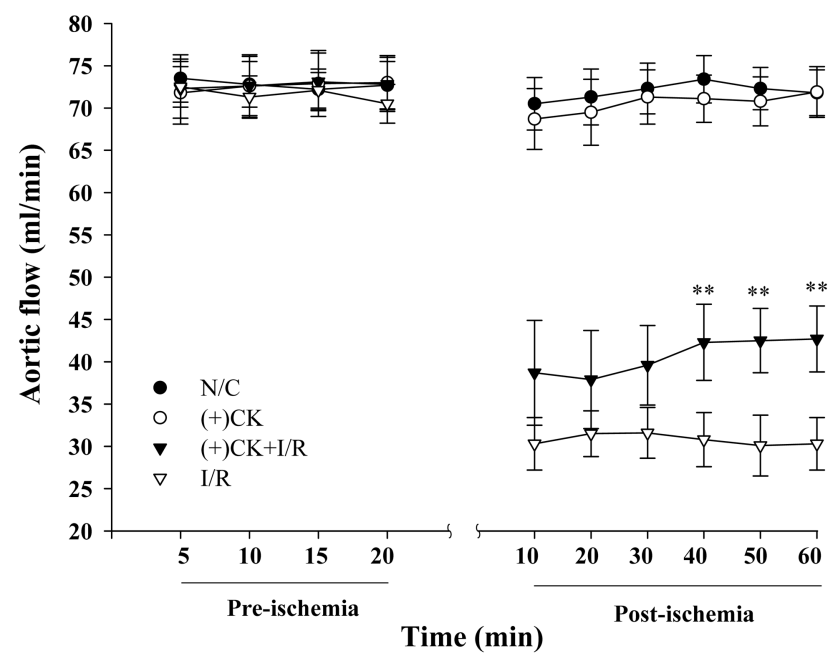

Fig. 5. Recovery effect of the CK on aortic flow of ischemiainduced isolated rat heart. Aortic flow was measured by timed collection of perfusate from the aortic cannula in each group to detect an anti-ischemia effect. Each symbol represents the mean \pm SEM from twelve rats per group with (O) denoting the normal control group without any treatment and ischemia (A1), (O) the treatment group of CK under normal conditions without ischemia (A2), ( $\nabla)$ the treatment group of CK under ischemic conditions (A3), and $(\nabla)$ the I/R group without any treatment. $* * p<0.01$ vs. control group under ischemic conditions based on Student's $t$-test.

Table 3. Effects of CK on aortic flow

\begin{tabular}{ccccc}
\hline \hline \multirow{2}{*}{ Time (min) } & \multicolumn{4}{c}{ Aortic flow for post-ischemia (ml/min) } \\
\cline { 2 - 5 } & N/C & CK & I/R & CK + I/R \\
\hline 10 & $70.5 \pm 3.1$ & $68.7 \pm 3.6$ & $30.3 \pm 3.1$ & $38.7 \pm 6.2$ \\
20 & $71.3 \pm 3.3$ & $69.5 \pm 3.9$ & $31.5 \pm 2.7$ & $37.9 \pm 5.8$ \\
30 & $72.3 \pm 3.0$ & $71.3 \pm 3.2$ & $30.8 \pm 3.2$ & $39.6 \pm 4.7$ \\
40 & $73.4 \pm 2.8$ & $71.1 \pm 2.8$ & $30.1 \pm 3.6$ & $42.3 \pm 4.5$ \\
50 & $72.3 \pm 2.5$ & 70.82 .9 & $30.3 \pm 3.1$ & $42.5 \pm 3.8$ \\
60 & $71.8 \pm 2.7$ & $71.9 \pm 3.0$ & $42.7 \pm 3.9$ \\
\hline
\end{tabular}

Table 4. Effects of CK on coronary flow

\begin{tabular}{ccccc}
\hline \hline \multirow{2}{*}{ Time $(\min )$} & \multicolumn{4}{c}{ Coronary flow for post-ischemia $(\mathrm{ml} / \mathrm{min})$} \\
\cline { 2 - 5 } & $\mathrm{N} / \mathrm{C}$ & $\mathrm{CK}$ & $\mathrm{I} / \mathrm{R}$ & $\mathrm{CK}+\mathrm{I} / \mathrm{R}$ \\
\hline 10 & $24.1 \pm 1.8$ & $24.5 \pm 2.7$ & $12.4 \pm 2.3$ & $15.4 \pm 3.6$ \\
20 & $23.7 \pm 1.3$ & $24.9 \pm 3.1$ & $12.7 \pm 2.1$ & $16.8 \pm 3.5$ \\
30 & $23.5 \pm 1.9$ & $25.1 \pm 3.3$ & $12.6 \pm 2.2$ & $17.6 \pm 2.8$ \\
40 & $23.7 \pm 1.6$ & $25.7 \pm 3.5$ & $12.2 \pm 2.3$ & $19.3 \pm 3.1$ \\
50 & $23.3 \pm 1.5$ & $25.5 \pm 3.8$ & $12.3 \pm 2.4$ & $19.4 \pm 2.7$ \\
60 & $22.8 \pm 1.9$ & $25.8 \pm 3.7$ & & $19.8 \pm 2.5$ \\
\hline
\end{tabular}




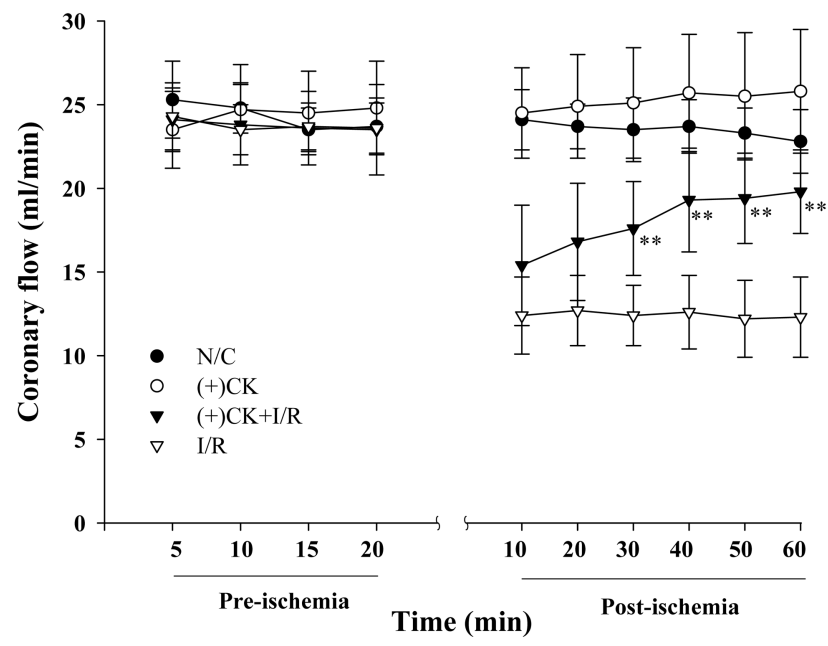

Fig. 6. Recovery effect of the CK on coronary flow of ischemiainduced isolated rat heart. Coronary flow was measured by timed collection of perfusate from pulmonary trunk in each group to detect an anti-ischemia effect. Each symbol represents the mean \pm SEM from twelve rats per group with (-) denoting the normal control group without any treatment and ischemia (A1), (O) the treatment group of CK under normal conditions without ischemia (A2), $(\boldsymbol{\nabla})$ the treatment group of CK under ischemic conditions (A3), and $(\nabla)$ the I/R group without any treatment. ${ }^{* *} p<0.01 v s$. control group under ischemic conditions based on Student's $t$-test.

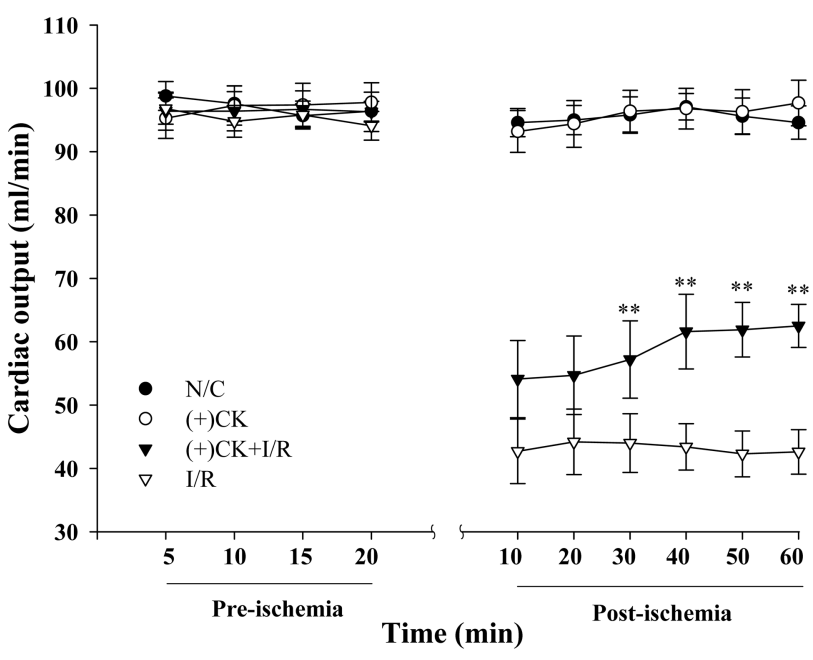

Fig. 7. Recovery effect of the CK on cardiac output of ischemiainduced isolated rat heart. Cardiac output was calculated by summing the aortic and coronary flows. Each symbol represents the mean \pm SEM from twelve rats per group with (๑) denoting the normal control group without any treatment and ischemia $(\mathrm{A} 1),(\mathrm{O})$ the treatment group of CK under normal conditions without ischemia (A2), ( $)$ the treatment group of $\mathrm{CK}$ under ischemic conditions (A3), and $(\nabla)$ the I/R group without any treatment. $* * p<0.01 v s$. control group under ischemic conditions based on Student's $t$-test.

Table 5. Effects of CK on cardiac output

\begin{tabular}{ccccc}
\hline \hline \multirow{2}{*}{ Time (min) } & \multicolumn{4}{c}{ Cardiac output for post-ischemia (ml/min) } \\
\cline { 2 - 5 } & N/C & CK & I/R & CK + I/R \\
\hline 10 & $94.6 \pm 2.2$ & $93.2 \pm 3.3$ & $42.7 \pm 5.1$ & $54.1 \pm 6.1$ \\
20 & $95.0 \pm 2.3$ & $94.4 \pm 3.7$ & $44.2 \pm 5.1$ & $54.7 \pm 6.2$ \\
30 & $95.8 \pm 2.8$ & $96.4 \pm 3.3$ & $44.0 \pm 4.6$ & $57.2 \pm 6.1$ \\
40 & $97.1 \pm 2.0$ & $96.8 \pm 3.2$ & $43.4 \pm 3.6$ & $61.6 \pm 5.9$ \\
50 & $95.6 \pm 2.8$ & $96.3 \pm 3.5$ & $42.3 \pm 3.6$ & $61.9 \pm 4.3$ \\
60 & $94.6 \pm 2.6$ & $97.7 \pm 3.6$ & $62.5 \pm 3.4$ \\
\hline
\end{tabular}

N/C: normal control, I/R: ischemia-reperfusion

CK significantly recovered decreases in cardiac output (**p<0.01, Table 5 and Fig. 7). Also, any effects of CK on cardiac output were not observed in corresponding times with ischemia group for 5 to 20 min during the preischemic period and 10 to $60 \mathrm{~min}$ during the postischemic period (normal control vs. CK, $p>0.05$, Tabel 5, Fig. 7).

\section{Size of infarct}

There was no significant difference in area at risk among normal control (A1), CK alone groups (A2). There were significant differences in infarct regions among $\mathrm{I} / \mathrm{R}$ group (A3) and CK treated group (A4). Compared to normal control as $100 \%, \mathrm{CK}$ treated group $(15.7 \% \pm 3.5 \%)$ decreased significantly in both infarct region compared with I/R group (38.3 $\pm 5.6 \%$ ) (Fig. 8).

The results from this study show that the CK significantly recovered the hemodynamics functions after $\mathrm{I} / \mathrm{R}$ injury (decreased perfusion pressure, aortic flow, coronary flow and cardiac output), but without influencing heart rate. One of the main indicators of ischemia-induced cardiac cell death is derived from the disturbance of intracellular $\mathrm{Ca}^{2+}$ homeostasis. Recent reports showed that under ischemic conditions, myocardial oxidative metabo- 


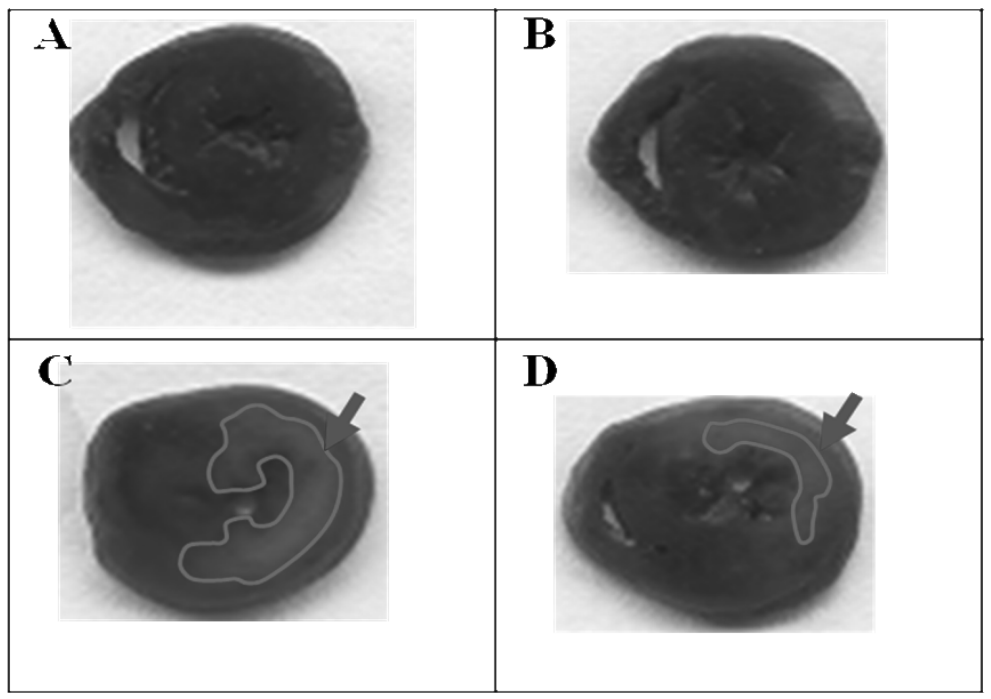

Fig. 8. Size of infarct region. A, the normal control group without any treatment and ischemia (A1); B, the treatment group of CK under normal conditions without ischemia (A2); $\mathbf{C}$, the I/R group without any treatment (A3); and $\mathbf{D}$, the treatment group of CK under ischemic conditions;. The white myocardium in the bottom slices (C and D) was identified as infarct region in which myocardium had been incubated in triphenyltetrazolium chloride phosphate buffered saline for 15 min. Treatment of CK decreased the area of infarct compared with normal control (D). Compared to normal control as $100 \%$, CK treated group decreased significantly in both infarct region compared with I/R group $(15.7 \% \pm 3.5 \%$ and $38.3 \pm 5.6 \%$, respectively, $p<0.01$, $\mathrm{n}=12$, each group).

lism is suppressed and glycolysis becomes an important source of ATP generation. ${ }^{20)}$ The increased glycolytic rate in the face of impaired glucose oxidation leads to uncoupling of the two pathways and a buildup of lactate and $\mathrm{H}^{+}$, a process that may continue during reperfusion. This accumulation of protons leads to downstream activation of pathways $\left(\mathrm{Na}^{+} / \mathrm{H}^{+}\right.$exchanger, $\mathrm{Na}^{+} / \mathrm{Ca}^{2+}$ exchanger) that result in $\mathrm{Ca}^{2+}$ overload, impaired contractile function, and/or cell death ${ }^{22)}$. Also, reactive oxygen species and metabolites are known to play important roles in the pathogenesis of $\mathrm{I} / \mathrm{R}$ and anoxia/reoxygenation injury. ${ }^{21)}$ The reduction of $\mathrm{O}_{2}$ results in the production of superoxides as well as hydrogen peroxide $\left(\mathrm{H}_{2} \mathrm{O}_{2}\right)$. $\mathrm{H}_{2} \mathrm{O}_{2}$ is highly diffusible and induces cell damage. $\mathrm{H}_{2} \mathrm{O}_{2}$ appears to affect not only lipids but also transmembrane proteins. The hydroxyl radical $(\mathrm{OH})$ also participates in lipid hyperoxidation. $^{21)}$ It was reported that in ischemia-reperfused heart, generation of reactive oxygen species and $\mathrm{Ca}^{2+}$ overload may correlate cardiac dysfunction. ${ }^{21-23)}$ Besides, in ischemia-reperfused cardiomyocytes, intracellular $\mathrm{Ca}^{2+}$ overload and reactive oxygen species production are suggested to be involved in the progression of apoptosis or necrosis, and may mediate signals to the nucleus, leading to altered gene transcription. ${ }^{24)}$ And, in the pathophysiology of ischemic contractile dysfunction, reactive oxygen species and intracellular $\mathrm{Ca}^{2+}$ overload modulate cardiomyocyte contractility through phosphorylation of various kinases, especially PKC and p38 kinase. ${ }^{25,26)}$ In addition, reactive oxygen species have been shown to interfere with $\mathrm{Ca}^{2+}$ transport systems across the sarcolemmal membrane. ${ }^{27,28)}$ Therefore, in present studies, the protective effects of CK might be due to modulation of any number of different physiological processes that are involved in the development of I/R injury. So, what is the mechanism underlying the protective effect of $\mathrm{CK}$ against ischemia-caused cardiac dysfunction ex vivo? One possibility is that these CK-induced protection against myocardial ischemia might be derived from the inhibition on ischemia-induced $\mathrm{Ca}^{2+}$ influx via $\mathrm{L}-$ and other types of $\mathrm{Ca}^{2+}$ channel since panaxadiol saponins and panaxatriol saponins block $\mathrm{Ca}^{2+}$ channel in the cultured cardiac cells ${ }^{29)}$ and ginsenoside block $\mathrm{Ca}^{2+}$ channel and anti-freeradical actions. ${ }^{30)}$ Also, we have shown that ginsenoside inhibit L-, $\mathrm{N}-$, and $\mathrm{P} / \mathrm{Q}$-types of $\mathrm{Ca}^{2+}$ channels ${ }^{31-34)}$ and CK inhibit voltage-dependent $\mathrm{Ca}^{2+}$ channel subtypes. ${ }^{18)}$ The second possibility is that myocardial protection of CK against cardiac I/R might be derived from the attenuation of oxidative stress caused by hypoxia, since ginsenosides inhibit overproduction of $\mathrm{NO}$ and malonyldiadehyde and prevented a decrease of superoxide dismutase activ- 
ity. ${ }^{30,35,36)}$ Given that ginsenosides possesses vasodilative properties, ${ }^{37,38)}$ this also may be a potential benefit of this agent against the 'no-reflow' in ischemic heart. In this study, the protective effects of CK lasted for at least 60 min in post-ischemic conditions. It is too early to say whether the pre-treatment of CK would continue to provide ongoing protection beyond this time point. Clearly, further studies are required to clarify these issues. Nevertheless, in present study we showed that $\mathrm{CK}$ is a compound without toxicity because of no difference in hemodynamic parameters between normal control and $\mathrm{CK}$ alone treatment, that provide protective effects in myocardium IR injury. These results demonstrate that $\mathrm{CK}$ have distinct anti-ischemic effects. However, the molecular mechanism of $\mathrm{CK}$ with respect to its anti-ischemic effects should be studied further before firm conclusions are drawn. In summary, using a rodent Langendorff model system that shows a mydiocardial I/R injury, we obtained results suggesting that $\mathrm{CK}$ has cardioprotective effects against myocardial I/R injury.

\section{CONCLUSIONS}

The anti-ischemic effects of CK on ischemia-induced isolated rat heart were investigated through analyses of changes in hemodynamic functions (perfusion pressure, aortic flow, coronary flow, and cardiac output). Treatment of CK significantly prevented decreases in hemodynamics under ischemic conditions. And, CK significantly limited the infarct. These results suggest that $\mathrm{CK}$ has distinct antiischemic effects. Also, these results support the development of a novel anti-ischemia agent based on the pharmacological actions of $\mathrm{CK}$.

\section{REFERENCES}

1. Sohn ES, Huh BY, Park SC, Park CW, Kim HJ. The effect of ginseng on blood pressure in spontaneous hypertensive rat and essential hypertension. Proceedings of the 3rd International Ginseng Symposium. Korean Gin Res Institute, Seoul, Korea. 1-3 (1980)

2. Kim ND, Kang SY, Schini VB. Ginsenosides evoke endothelium-dependent vascular relaxation in rat aorta. Gen Pharmacol. 25: 1071-1077 (1994)

3. Shibata S, Tanaka O, Ando T, Sado M, Tsushima S, Ohsawa T. Chemial studies on oriental plant drugs. XIV. Protopanaxadiol, a genuine sapogenin of ginseng saponins. Chem Pharm Bull. 14: 595-600 (1966)

4. Toda N, Ayajiki K, Fujioka H, Okamura T. Ginsenoside potentiates NO-mediated neurogenic vasodilatation of mon- key cerebral arteries. J Ethnopharmacol. 76: 109-113 (2001).

5. Kim ND, Kang SY, Kim MJ, Park JH, Schini-Kerth VB. The ginsenoside $\mathrm{Rg}_{3}$ evokes endothelium-independent relaxation in rat aorti rings:role of $\mathrm{K}^{+}$channels. Eur J Pharmacol. 367: 51-57 (1999a)

6. Kim ND, Kang SY, Park JH, Schini-Kerth VB. Ginsenoside $\mathrm{Rg}_{3}$ mediates endothelium-dependent relaxation in response to ginsenosides in rat aorta: role of $\mathrm{K}^{+}$channels. Eur J Pharmacol. 367: 41-49 (1999b)

7. Shen AC, Jennings RB. Kinetics of calcium accumulation in acute myocardial ischemic injury. Am J Pathol. 67: 441-452 (1972)

8. Shen AC, Jennings RB. Myocardial calcium and magnesium in acute ischemic injury. Am. J. Pathol. 67: 417-440 (1972)

9. Bourdillon PD, Poole-Wilson PA. Effects of ischaemia and reperfusion on calcium exchange and mechanical function in isolated rabbit myocardium. Cardiovasc Res. 15: 121-130 (1981)

10. An J, Varadarajan SG, Camara A. Blocking $\mathrm{Na}^{+} / \mathrm{H}^{+}$exchange reduces $\left[\mathrm{Na}^{+}\right]_{\mathrm{i}}$ and $\left[\mathrm{Ca}^{2+}\right]_{\mathrm{i}}$ load after ischemia and improves function in intact hearts. Am J Physiol. 281: H2396-H2409 (2001)

11. Sun HY, Wang NP, Halkos ME. Involvement of $\mathrm{Na}^{+} / \mathrm{H}^{+}$ exchanger in hypoxia/re-oxygenation-induced neonatal rat cardiomyocyte apoptosis. Eur J Pharmacol. 486: 121-131 (2004)

12. Micheal PH, Meuter K, Schasfer C. Cellular mechanisms of ischemia-reperfusion injury. Ann Thorac Surg. 75: S644S648 (2003)

13. Maulik N, Yoshida T, Das DK. Oxidative stress developed during the reperfusion of ischemic myocardium induces apoptosis. Free Radiac Biol Med. 24: 869-875 (1998)

14. Sun J, Tan BK, Huang SH, Whiteman M, Xhu YZ. Effects of natural products on ischemic heart diseases and cardiovascular system. Acta Pharmacol Sin. 23: 1142-1151 (2002)

15. Lee JH, Jeong SM, Kim JH, Lee BH, Yoon IS, Lee JH, Choi SH, Lee SM, Park YS, Lee JH, Kim SS, Kim HC, Lee BY, Nah SY. Effects of Ginsenosides and Their Metabolites on Voltage dependent $\mathrm{Ca}^{2+}$ Channel Subtypes. Mol Cells 21 (No. 1): 52-62 (2006)

16. Li XS, Urriuda Y, Wang QD, Norlander R, Sjoouist PO, Pernow J. Role of L-arginine in preventing myocardial and endothelial injury following ischaemia/ reperfusion in the rat isolated heart. Acta Physiol Scand. 156: 37-44 (1996)

17. Zhao JL, Yang YJ, Chen JL, Kang LM, Wu Y, Gao RL. Nicorandil reduces myocardial no-reflow by protection of endothelial function via the activation of KATP channel. Clin Chim Acta. 374: 100-105 (2006)

18. Yu XC, Wu S, Wang GY, Shan J, Wong TM, Chen CF, Pang KT. Cardiac effects of the extract and active components of radix stephaniae tetrandrae. II. Myocardial infarct, arrhythmias, coronary arterial flow and heart rate in the isolated per- 
fused rat heart. Life Sci. 68: 2863-2872 (2001)

19. Galagudza M, Kurapeev D, Minasian S, Valen G, Vaage J. Ischemic postconditioning: brief ischemia during reperfusion converts persistent ventricular fibrillation into regular rhythm. Eur J Cardiothorac Surg. 25: 1006-1010 (2004)

20. Asano G, Takashi E, Ishiwata T, Onda M, Yokoyama M, Naito Z, Ashraf M, Sugisaki Y. Pathogenesis and protection of ischemia and reperfusion injury in myocardium. J Nippon Med Sch. 70: 384-392 (2003)

21. Ferrari R, Alfieri O, Curello S, Ceconi C, Cargnoni A, Marzollo P, Pardini A, Caradonna E, Visioli O. Occurrence of oxidative stress during reperfusion of the human heart. Circulation 81: 201-211 (1990)

22. Temsah RM, Netticadan T, Chapman D, Takeda S, Mochizuki S, Dhalla NS. Alterations in sarcoplasmic reticulum function and gene expression in ischemic-reperfused rat heart. Am J Physiol. 277: H584-H594 (1999)

23. Bolli R, Marbán E. Molecular and cellular mechanisms of myocardial stunning. Physiol Rev. 29: 610-636 (1999)

24. Sharikabad MN, Hagelin EM, Hagberg IA, Lyberg T, Brors O. Effect of calcium on reactive oxygen species in isolated rat cardiomyocytes during hypoxia and reoxygenation. J Mol Cell Cardiol. 32: 441-452 (2000)

25. Wang YG, Benedict WJ, Huser J, Samarel AM, Blatter LA, Lipsius SL. Brief rapid pacing depresses contractile function via $\mathrm{Ca}(2+) / \mathrm{PKC}$-dependent signaling in cat ventricular myocytes. Am J Physiol Heart Circ Physiol. 280: H90-H98 (2001)

26. Liao P, Wang SQ, Wang S, Zheng M, Zheng M, Zhang SJ, Cheng H, Wang Y, Xiao RP. p38 mitogen-activated protein kinase mediates a negative inotropic effect in cardiac myocytes. Circ Res. 90: 190-196 (2002)

27. Kaneko M, Beamish RE, Dhalla NS. Depression of heart sarcolemmal $\mathrm{Ca}^{2+}$-pump activity by oxygen free radicals. Am $\mathrm{J}$ Physiol. 256: H368-H374 (1989a)

28. Kaneko M, Elimban V, Dhalla NS. Mechanism for depression of heart sarcolemmal $\mathrm{Ca}^{2+}$ pump by oxygen free radi- cals. Am J Physiol. 257: H804-H811 (1989b)

29. Jiang Y, Zhong G, Shao C, Yue G. $\mathrm{Ca}^{2+}$ channel blocking effect of panaxadiol saponins and panaxatriol saponins of cultured cardiac cells. Zhongguo Zhong Yao Za Zhi. 192 Mar 17(3): 172-173 (1992)

30. Zhong G, Jiang Y. Calcium channel blockage and anti-freeradical actions of ginsenosides. Chin Med J (Engl). Jan 110(1): 28-29 (1997)

31. Nah S, Park HJ, McCleskey EW. A trace component of ginseng that inhibits $\mathrm{Ca}^{2+}$ channels through a pertussis toxinsensitive G protein. Proc Natl Acad Sci. 92: 8739-8743 (1995)

32. Kim HS, Lee JH, Koo YS, Nah SY. Effects of ginsenosides on $\mathrm{Ca}^{2+}$ channels and membrane capacitance in rat adrenal chromaffin cells. Br Res Bull. 46: 245-251 (1998a)

33. Rhim H, Kim H, Lee DY, Oh TH, Nah SY. Ginseng and ginsenoside $\operatorname{Rg}_{3}$, a newly identified active ingredient of ginseng, modulate $\mathrm{Ca}^{2+}$ channel currents in rat sensory neurons. Eur J Pharmacol. 436: 151-158 (2002)

34. Nah SY, McCleskey EW. Ginseng root extract inhibits calcium channels in rat sensory neurons through a similar path, but different receptor, as type opioids. J Ethnopharmacol. 42: 45-51 (1994)

35. Chu GX, Chen X. Anti-lipid peroxidation and protection of ginsenosides against cerebral ischemia-reperfusion injury of rats. Acta Pharma Sin. 11: 119-123 (1990)

36. Chu GX, Chen X. Protective effect of ginsenosides on acute cerebral ischemia-reperfusion injury of rats. Cha J Pharmacol Toxicol. 3: 18-23 (1989)

37. Kim ND, Kang SY, Schini VB. Ginsenosides evoke endothelium-dependent vascular relaxation in rat aorta. Gen Pharmacol. Oct 25(6): 1071-1077 (1994)

38. Toda N, Ayajiki K, Fujioka H, Okamura T. Ginsenoside potentiates NO-mediated neurogenic vasodilatation of monkey cerebral arteries. J Ethnopharmacol. Jun 76(1): 109-113 (2001) 